\title{
MEMORIAS E IMAGINARIOS DE FORMACIÓN DE LOS HIJOS EN LA NARRATIVA CHILENA RECIENTE ${ }^{1}$
}

\author{
María Angélica Franken Osorio \\ Universidad de Chile/ Universidad Adolfo Ibáñez, Santiago de Chile, Chile \\ angiefranken@gmail.com
}

\section{RESUMEN / ABSTRACT}

Este análisis explora la narrativa chilena reciente que rememora el pasado de infancia en dictadura -la llamada literatura de los hijos- estableciendo un vínculo estético y discursivo entre una memoria compartida y los imaginarios de formación de quienes fueron niños en el pasado dictatorial y son escritores en el presente posdictatorial. La continuidad afectiva de un conflicto, entre un tiempo presente de la memoria y un tiempo pasado de aprendizaje infantil aún incompleto o por comprender, explica la perspectiva escogida de hijos de los narradores de algunas obras ficcionales de Nona Fernández (1971), Álvaro Bisama (1975) y Alejandro Zambra (1975). En las tres construcciones imaginarias específicas que se recorren en las siguientes páginas, se da cuenta de la intención de estos escritores de articular -en la ficción- los imaginarios de infancia que establezcan y expliquen sus actuales posiciones sociales, intelectuales y afectivas.

PALABRAS ClAVE: infancia, memoria, imaginarios de formación, narrativa chilena reciente.

\section{Memories and Development Imaginaries of the Children in Recent Chilean FICTION}

The following paper explores the recent Chilean narrative which recalls childhood during the dictatorship, the so-called "literatura de los hijos" (literature of sons and daughters), establishing an aesthetic and discoursive link between shared memory and the development imaginaries of those who were children during the dictatorial past and that are writers in

1 Un extracto este artículo fue presentado en el XX Congreso Internacional de la Sociedad Chilena de Estudios Literarios con sede en la Universidad de Chile durante los días $25,26,27$ y 28 de octubre de 2016 . 
the post-dictatorial present. The affective continuity of a conflict, between a present state of memory and a past of childhood learning, still incomplete or with potential for understanding, explains the perspective chosen of sons and daughters of the narrators in some of the fictional works by Nona Fernández (1971), Álvaro Bisama (1975), and Alejandro Zambra (1975). In the three imaginary constructions explored in the following pages, the aim of these authors is described, in terms of their intention to articulate, within fiction, childhood imaginaries that establish and explain their current social, intellectual, and affective positions.

KEYWORDS: childhood, memory, development imaginaries, recent Chilean narrative.

Recepción: 24/04/2017

Aprobación: 12/07/2017

\section{INTRODUCCIÓN: LA NARRATIVA DE LOS HIJOS}

En el ámbito de la literatura chilena reciente, una generación de escritores que fueron niños o adolescentes durante la dictadura militar (1973-1989) de Augusto Pinochet, han rearticulado sus experiencias de ese periodo desde la ficción novelesca. Aunque no son autobiografías o memorias propiamente tales, pertenecen a las denominadas literaturas del yo que problematizan las barreras permeables entre lo real y lo ficticio. De ello surge un interés crítico $^{2}$ por este conjunto de novelas que tienen como protagonistas a niños y adolescentes, y en las cuales la experiencia de la dictadura y la posdictadura estructura sus relatos filiativos y de formación ${ }^{3}$, marcadamente autorreflexivos. La perspectiva escogida del hijo los sitúa en una posición crítica que abre la discusión estética y ética sobre esta elección, problematizando las anteriores $\mathrm{y}$ actuales representaciones de la memoria sobre el pasado reciente.

Para estas novelas, la construcción ficcional de la memoria no se articula como un relato coherente y cronológico, sino que se estetiza justamente

\footnotetext{
El vínculo entre la infancia y las memorias recientes ha sido destacado por diversos estudios académicos (Lorena Amaro 2014, Ignacio Álvarez 2013, Alejandra Botinnelli 2016, Rubí Carreño 2009, Andrea Jeftanovich 2011, Sergio Rojas 2015, entre otros) que han trabajado con la perspectiva de los niños e hijos.

Los relatos analizados no son posibles de insertar en la categoría genérica cerrada de los Bildungsromane, sino en una más abierta -relatos de formación- que dialoga con algunos elementos de este género discursivo, pero también con la autobiografía, las memorias, la picaresca, el melodrama, entre otros.
} 
como una suerte de ruina, es decir, como una serie de capas de sentido y de significaciones que permiten acceder al pasado, pero siempre de modo incompleto y mediado. Por lo mismo, la memoria es entendida y construida, por estos autores, como un proceso y no como un acontecimiento siguiendo al teórico Walter Benjamin (Sobre el concepto de historia). Lo que estos autores realizan, en sus obras ficcionales, es la actualización del origen traumático -golpe militar- en un conflicto particular que se traduce en la tensión y negociación con la serie de imaginarios formativos de la dictadura y la posdictadura que siguen sintiéndose y transformándose en el presente. Por ello, los relatos de los hijos corresponden a fragmentos, pedazos, ideas-imágenes sociales y culturales mediadas del pasado que se expresan estéticamente en murmullos, ruidos, sueños y pesadillas, y que se articulan, con más o menos ilación y continuidad, en torno a los afectos de la culpa, la nostalgia y la incomodidad.

A fin de cuentas, en estas obras, no se trata de la historia de los hijos en el sentido tradicional y moderno del concepto, sino de la memoria de los hijos construida desde la ficcionalización de la experiencia infantil. No es una memoria en segundo grado -posmemoria, en los términos planteados por Marianne Hirsch ${ }^{4}$ (La generación de la posmemoria)- o de menor valor que la de los padres, sino otra memoria, diferente y articulada desde la mirada del hijo y su necesidad actual de comunicar la experiencia, puesto que para éste la infancia y dictadura, sentida como afecto, no ha finalizado o no fue vivida de una manera deseada. La construcción de una subjetividad infantil -infancia, experiencia y lenguaje (Agamben, Infancia e Historia)- parece ser la única estrategia estética y discursiva capaz de volver a vincular el potencial de subjetividad del cual habla Sergio Rojas en su artículo "Profunda superficie: memoria de lo cotidiano en la literatura chilena" (2015), el que se rompe con el golpe militar, y que dota a la memoria del lugar de la historia (235). Ahora bien, los hijos sí son capaces de articular un relato que dote de sentido y significado una experiencia que se ha vivido en segundo lugar o vicariamente, pero es uno que se sabe, desde sus inicios, fracturado y mediado.

$4 \quad$ El concepto de "posmemoria" que articula Marianne Hirsch se estructura en función de la distancia temporal y actancial del que habla respecto de los hechos traumáticos. Por ello, la autora habla de la segunda generación, la de los hijos de sobrevivientos o fallecidos en el Holocausto judío. 
Por lo mencionado, los hijos rearticulan y problematizan los imaginarios formativos y filiativos de su infancia en la década de los 80 -los marcos sociales modernos de la familia, escuela y religión en términos de E. Jelin (Los trabajos de la memoria)- estableciendo nuevas lecturas y resignificaciones de ese periodo. A pesar de la presencia central de la figura de los progenitores en varias novelas, la filiación va más allá de los padres, y se alude más bien a la (a)filiación, siguiendo a E. Said, a un proyecto, a una comunidad, a una generación, a un orden compensatorio que involucre una nueva visión de mundo (34). En este sentido, no son relatos de filiación propiamente tales: hay una pregunta por la herencia, pero es una de carácter colectiva y social. Entonces, si se habla de herencia, sería más bien de una cultural y construida, en conjunto, como un imaginario discursivo, como una serie de ideas-imágenes que aparecen a modo de pesadillas, ruidos, sueños, recuerdos, objetos y cuerpos.

Por último, la definición que establece Bronislaw Bazcko en su libro Los imaginarios sociales. Memorias y esperanzas colectivas (1984) resulta operativa para este análisis. "A lo largo de la historia, las sociedades se entregan a una invención permanente de sus propias representaciones globales, otras tantas ideas-imágenes a través de las cuales se dan una identidad, perciben sus divisiones, legitiman su poder o elaboran modelos formadores para sus ciudadanos [...]" (8). La noción de "ideas-imágenes" resulta particularmente interesante para el análisis del imaginario de los hijos en literatura porque imbrica la palabra y el conocimiento con su proyección virtual, e introduce el eje sociológico de la identidad al problema estético y discursivo de la memoria. Tanto Bazcko como Magda Sepúlveda en su artículo "La construcción de identidades, sus imaginarios y su posición en la literatura" (2003) enfatizan la idea recogida de que en la construcción discursiva-literaria de los imaginarios sociales hay siempre tensiones y conflictos de poder entre las subjetividades individuales y las colectivas. En este sentido, los imaginarios dan cuenta de las tensiones palpables en los discursos de los narradores-protagonistas, entre su imagen del "yo" y la proyección - más o menos mediada- del "nosotros" que articulan en sus relatos, con mayor o menor conciencia de ello.

Lo anterior se comprende si se afirma ya de antemano que es posible identificar una intención -al menos en los tres escritores analizados en estas páginas y en el grupo generacional al que pertenecen- de articular no una Historia -esa fue/es la labor de los padres, según los mismos-, pero sí un imaginario de la infancia en dictadura que los resitúe ética, social y artísticamente en la actualidad. En este sentido, se podría ya afirmar que los 
escritores están negociando su perspectiva del pasado dictatorial, la que está en tensión con los otros discursos -institucionales o no- que circulan sobre el pasado reciente. En este sentido, los hijos se establecen como una suerte de mediadores entre una experiencia individual y de corte filiativa y una comunitaria y de corte afiliativo, una "memoria compartida" en términos de Doll (2017) , que se establece como un tercer lugar que recoge a ambas y que refiere a ideas-imágenes comunes a un grupo o generación, pero que son experimentadas diferentes en cada caso particular. Por esto, los mismos hijos establecen qué entra y qué no dentro del gran imaginario epocal de los niños nacidos en dictadura, legitiman o rechazan otros discursos, desprecian o problematizan subjetividades, por lo que su accionar es siempre e inevitablemente sospechoso o, al menos, problemático. La perspectiva testimonial y de memoria ${ }^{6}$, en la mayoría de sus obras, de los autores de este análisis propuesto -Nona Fernández (1971), Álvaro Bisama (1975) y Alejandro Zambra (1975) - valida éticamente la perspectiva de sus producciones y los sitúa en un lugar ya reconocido y afectivo para acceder a la historia nacional, no obstante, no hay duda del ejercicio de poder presente.

\section{“AÚN ÉRAMOS DEMASIADO NIÑOS”: NIÑOS QUE JUEGAN Y MUEREN}

La novela Space Invaders (2013) de Nona Fernández (1971), al igual que el juego llamado de la misma forma, se divide en vidas -"Primera Vida", "Segunda Vida", "Tercera Vida" y "Game over". Cada una de éstas transcurre en el espacio-tiempo de la década de los 80 en una escuela de Avenida Matta, y sus protagonistas son los compañeros de curso que van creciendo y, particularmente, la niña Estrella González que es la que muere

Este concepto de "memoria compartida" fue presentado y discutido por Darcie Doll y otros en el Coloquio "Aproximación a las Narrativas de los Hijos y Memoria en Chile y Argentina”, el martes 18 de abril de 2017, en la Facultad de Filosofía y Humanidades de la Universidad de Chile.

$6 \quad$ La antología Volver a los 17. Recuerdos de una generación en dictadura (2013) de Óscar Contardo introduce a estos mismos autores y a muchos otros de los nacidos entre 1969 y 1979 (Andrea Jeftanovich, Alejandra Costamagna, Rafael Gumucio, entre otros) dentro de un grupo identificable, y establece sus crónicas/memorias como un modo válido de acceder al pasado de infancia en dictadura. 
al final del relato. La perspectiva y lógica del juego -entendido como ocio o como representación (Huizinga, Homo ludens)- configura toda la historia de formación de los niños protagonistas y que implica, entre otras aventuras, la salida del espacio protegido de la escuela ${ }^{7}$ a la calle en el contexto de los movimientos estudiantiles de los años $80^{8}$.

El primer caso corresponde al del estudiante Zúñiga que ayuda a su hermano mayor en una acción de protesta en el marco del inicio de los movimientos sociales contra Pinochet.

Llevamos panfletos en nuestros bolsones [...] Debemos tirarlos en el frontis del liceo sin que nadie nos vea. No sé bien lo que dicen, parece que habla de una marcha, son la citación a una gran marcha contra Pinochet, algo nunca visto, algo nunca hecho, algo muy importante porque mi hermano grande me pidió que hiciera esto y cuando lo hizo dijo que era una misión únicamente para valientes, así es que puedo hacer esto y más (42).

Zúñiga realiza la tarea de valientes a cambio del premio de un niño: primero, el álbum de otro juego, el de la selección chilena en el Mundial de Fútbol de España del año 82; dos, un paseo en el Chevette rojo del tío Claudio, desconociendo el peligro real que significa el tío de Estrella. Esta primera salida a la calle como espacio de intercambio de identidades e ideologías introduce en el espacio protegido de la sala de clases el componente político y sus respectivos silencios:

Que Zúñiga y Riquelme hicieron algo malo. Que parece que los pillaron en algo terrible, que por eso los suspendieron un par de días, que por eso no han venido, dice Maldonado. Que Zúñiga anda metido en política, que por eso le pasa lo que le pasa, responde Acosta. Que qué es que esté metido en política, pregunta Donoso. Que no puede ser que ande metido en política porque es muy chico, dice Maldonado [...] Que anda enchufándote porque no somos tan chicos, responde Bustamente $[\ldots]$ Que profesor, que antes de empezar queremos

7 Tanto en el cuento "Hijos" antalogado en Volver a los 17. Recuerdos de una generación en dictadura (2013) como en la pieza teatral Liceo de Niñas (2016), la infancia como espacio protegido es puesta en peligro en la violenta salida de la escuela a la calle.

Me refiero al emblemático movimiento secundario que tuvo su protagonismo entre los años 1983 y 1988, y que tenía como fin central luchar contra la municipalización de la educación pública y contribuir a desestabilizar el régimen militar. 
hacerle una pregunta. Que qué pregunta quieren hacer. Que qué es meterse en política. Que qué edad hay que tener para poder hacerlo. Que silencio. Que el profesor mira desconcertado. Que silencio [...] (Fernández 48-9).

Nona Fernández afirma, en una entrevista, que "los niños éramos así, súper niños" (Sepúlveda Hidalgo 258). Eran muy niños y se enfrentaron a los silencios de los adultos y de sus educadores ${ }^{9}$. Los niños no reciben las respuestas, pero pareciera que tampoco serían capaces de entender éstas.

Los niños de Space Invaders juegan un juego del que, paradójicamente, desconocen las reglas: "Formamos un cuadrado perfecto, una especie de tablero. Somos las piezas de un juego, pero no sabemos cuál" (Fernández 17). Si en las representaciones escolares de la Guerra del Pacífico había cierta conciencia del peligro que vivieron los que murieron en batalla por la patria, en la salida a la calle y, por consecuencia, a lo político, no era así.

No entendemos bien de qué se trata, pero lo hacemos. Aullamos un alarido que sale más allá de nuestras bocas, una consigna inventada y convocada por otros, pero hecha para nosotros [...] Varias columnas formando un cuadrado eterno y perfecto, un bloque que avanza al mismo tiempo, un solo cuerpo moviéndose en el tablero. Somos la gran pieza de un tablero, pero todavía no sabemos cuál (53).

Entonces, la "sala de clases se abrió a la calle y desesperados e ingenuos saltamos a la cubierta del barco enemigo en un primer y último intento condenado al fracaso" (58). En la vida real, el salto al barco enemigo se traduce en muerte y, en el proceso de formación de los niños, la conciencia de la muerte implica un acercamiento mayor a la adultez:

Ninguno tiene claro el momento exacto, pero todos recordamos que de golpe aparecieron ataúdes y funerales y coronas de flores y ya no pudimos huir de eso, porque todo se había transformado en algo así como un mal sueño. A lo mejor siempre había sido así y no nos

9 Esta escena escolar dialoga directamente con la que imagina Alejandro Zambra en Formas de volver a casa (2012): los silencios atemorizados de los maestros del Instituto Nacional, y los niños que preguntan y no entienden la respuesta, pero sienten empatía por el miedo ajeno. 
habíamos dado cuenta. A lo mejor, Maldonado tenía razón y antes éramos muy chicos (58).

En la parte titulada la "Tercera Vida", cuando los protagonistas tienen aproximadamente 15 años, los muertos ya no se podían obviar y la invasión de la dictadura en el espacio íntimo -el de la casa y la familia- era imposible de evitar. Hubo un cambio de la "concepción espacial del tiempo (casa-familia) por la idea secuencial que implica, en parte, la adultez; el olvido y la muerte" (Vásquez 317). Por lo mismo, en la perspectiva desde la adultez, se asocia el recuerdo a la muerte: "El tiempo no es claro, todo lo confunde, revuelve los muertos, los transforma en uno, los vuelve a separar, avanza hacia atrás, retrocede al revés, gira como en un carrusel de feria [...] Si estuvimos ahí o no, ya no es claro" (Fernández 61). Recordar y el tiempo del recuerdo están vinculados a la adultez y a una estrategia de la memoria que tiene sus lógicas temporales propias e inciertas.

A lo largo de Space Invaders, los niños juegan distintos juegos, con más o menos conciencia de las reglas que los rigen. Sin embargo, estos alumnos de la escuela pública mueren en batalla como, por ejemplo, los hermanos Vergara Toledo:

Santiago de Chile. Año 1985. El 29 de marzo los jóvenes hermanos Rafael y Eduardo Vergara Toledo, de dieciocho y veinte años respectivamente, mueren baleados por agentes de Carabineros en la Villa Francia. Ambos habrían tenido que abandonar sus estudios por sus vínculos políticos, siendo acusados de agitadores y panfleteros (57).

Durante la dictadura, la muerte de los adolescentes Vergara Toledo, vinculados al movimiento secundario de los años 80 , se va a unir a la imagen del hijo adolescente de uno de los degollados en el año 1985, y en el imaginario de los niños actores, también a las víctimas infantiles de la Guerra del Pacífico que:

[...] a lo mejor solo eran como nosotros, un ejército de adolescentes, punta de lanza barata con apellidos de mierda, provenientes de un liceo de mierda, sin tradición ni vista de la cordillera, sin idiomas extranjeros con los que defenderse, cabecitas negras tirándose a la piscina sin salvavidas, a poto pelado, preparando el territorio para los otros, siempre para los otros. Soldaditos de plomo chapoteando en este mar falso sin tener mucha idea de qué batalla pelean (66). 
La última muerte, la más simbólica, es la de Estrella, la principal protagonista del relato, cuyo vínculo directo con lo político - un padre asesino por encargoes desconocido para sus compañeros. Es una muerte melodramática, por el mal de amores. La violencia de género y la teatralidad de su muerte no tiene justificativo alguno más que en la lógica asesina del padre y la dictadura. En este sentido, se conecta a los niños que murieron en el campo de batalla de la Guerra del Pacífico o en el de la dictadura: niños que jugaron un juego del cual no sabían bien las reglas. Víctimas sin sentido que mueren cuando ya ha finalizado la batalla y su tiempo específico y reglamentado.

Santiago de Chile. Año 1991. Una mañana de octubre, el teniente de Carabineros Félix Sazo Sepúlveda ingresa al Hotel Crown Plaza del centro de Santiago. Con rapidez el teniente se dirige al mostrador de las oficinas de Avis Rent a Car, donde atiende Estrella González Jepssen [...] Sazo se detiene frente a ella y la apunta con su arma de servicio. Hace un tiempo que están separados [...] Estrella, le grita. Nuestra joven compañera apenas alcanza a mirarlo cuando recibe dos balazos en el pecho, uno en la cabeza y un cuarto en la espalda. Como un marcianito se desarticula en luces coloradas. El tablero de la pantalla marca cien puntos más para el score (73).

Igual que en el juego Space Invaders, Estrella muere a tiros dentro de la lógica asesina de un juego que ya había acabado, pero que es finalmente un juego sucio cuyas dinámicas siguen tras su finalización y, por ello, continúa teniendo atrapados a sus jugadores principales: "Formamos un cuadrado perfecto, una especie de tablero. Somos las piezas de un juego que no sabemos dejar atrás [...] Solo nosotros y esta lógica de guerrilla de la que no logramos despertar" (77).

Los narradores adultos de Space Invaders recuerdan a Estrella González y el periodo en la escuela, pero este recuerdo es plasmado estéticamente como un sueño -voces e imágenes- y problematizado dentro del mismo relato. Para el narrador adulto, la distinción entre soñar y recordar pasa a segundo plano, lo relevante pareciera ser que hay recuerdos y sueños/pesadillas que no dejan dormir aún en el presente.

No sabemos si esto es un sueño o un recuerdo. A ratos creemos que es un recuerdo que se nos mete en los sueños, una escena que se escapa de la memoria de alguno y se esconde entre las sábanas sucias de todos. Pudo ser vivida ya, por nosotros o por otros. Pudo ser representada y hasta inventada, pero mientras más lo pensamos creemos que sólo 
es un sueño que se ha ido transformando en recuerdo. Si hubiera una diferencia entre unos y otros, podríamos identificar de dónde salió, pero en nuestro colchón desmemoriado todo se confunde y la verdad es que ahora eso poco importa (41).

Pareciera que Nona Fernández da respuesta a la persistencia del conflicto entre el presente y el pasado, al conflicto afectivo de la memoria, elaborando estética y discursivamente la lógica de los sueños y los recuerdos conformados por imágenes y voces, puesto "[q]ue mientras ella escucha voces, [y] otros solo ven imágenes" (19). Los sueños, así como los recuerdos, tienen un origen y final incierto y abierto, y "son diversos, como diversas son nuestras cabezas, y diversos son nuestros recuerdos, y diversos somos y diversos crecimos. Desde nuestra onírica diversidad podemos concordar que cada uno a su propio modo la ve como la recuerda" (14). Por lo mismo, "en los sueños, lo mismo que en los recuerdos, no puede ni debe haber consenso posible" (15) ya que "[t]odo es relativo, menos el sonido de su voz, que cuando se trata de sueños, según Fuenzalida, es lo mismo que la huella digital” (15). La única certidumbre es la existencia de una voz que se recuerda, entonces, ya no es un sueño o solo sueño.

Fernández opta por resignificar la derrota pasada del juego juvenil -movimiento secundario - en la pesadilla, en las ideas-imágenes de la discontinuidad y la ruptura. En este sentido, las diversas ideas-imágenes que recorren su obra en general: "la muerte", "los jóvenes/héroes caídos", "los hijos de degollados que no lloran", "los estudiantes que sufren una derrota", son los modos de comprender y de articular una explicación, "éramos demasiado niños", a ciertos protagonismos y derrotas históricas. Por ello, en Space invaders se articula un relato discontinuo y fragmentado que explica/justifica la lógica de lucha que aún persiste: "Estoy sometido a este sueño: sé que no es más que un sueño, pero no puedo escapar de él" (9). Entonces, el afecto de antaño respecto a la muerte y al juego de combate, sigue reproduciéndose en un presente que accede de forma imaginaria al pasado. De este modo, sus procesos e imaginarios de formación juvenil siguen reactualizándose en la adultez. Por ello, los niños/hijos del pasado continúan articulando una memoria fragmentada de ideas-imágenes desde su condición en el presente de hijos. Hijos que fueron en el pasado "demasiado niños", y que se reconocen en el modo de contar y recordar y que, en el caso de Fernández, renuncian a la continuidad de la Historia para construirse desde la subjetividad escritural. 


\section{"LA VIRGEN SE LE APARECÍA A UN NIÑO”: EL TEDIO Y EL RUIDO DE LA PROVINCIA}

En la novela Ruido (2012) del escritor Álvaro Bisama (1975), aparece una idea-imagen central: el personaje marginal que recorre otras obras del autor y es la de Miguel Ángel Poblete (1966-2008), el vidente de Peñablanca. Es decir, la del joven huérfano que entre los años 1983-1988 protagonizó las visiones de la Virgen de Peñablanca en el cerro Membrillar, llamado posteriormente Montecarmelo. Las apariciones fueron desestimadas por la Iglesia Católica tras una investigación eclesial e incluso se afirmó la manipulación de los servicios de inteligencia de la dictadura; no obstante, ciertos grupos continuaron con el fervor mariano tras el año 1988 y se siguieron reuniendo en torno a Miguel Ángel que, ya a principios de la década del 2000, se reconoce abiertamente mujer y se renombra Karol Romanoff. A fines de la misma década, muere, en condiciones precarias, de una insuficiencia hepática, provocada por un alcoholismo de años, y lo rodean sus fieles seguidoras que se agrupaban con el nombre "Los apóstoles de los últimos tiempos".

La envergadura del hecho histórico y religioso trasciende al social y cultural por las repercusiones que tuvo el caso en la comunidad de Peñablanca y en el imaginario de los chilenos durante la década de $\operatorname{los} 80^{10}$. Ahora bien, tras leer unas cuantas páginas de Ruido, no cabe duda de que el protagonista del relato no es el vidente de Peñablanca, sino la provincia chilena y la voz colectiva, un "nosotros" que no deja de murmurar y pelear con el ruido. Entonces, desde un presente enunciativo, la voz colectiva rememora la provincia chilena durante los años 80, a los niños y adolescentes que presenciaron las apariciones de la Dama de la Paz entre junio de 1983 y junio de 1988. Pareciera que esta voz plural recoge a aquéllos que no estuvieron en los periódicos del periodo, los "nosotros" que no formaron parte del relato nacional oficial, a diferencia de los "ellos", Miguel Ángel y sus discípulos en el cerro Montecarmelo, que quedaron, para siempre, en el imaginario del país y en la crónica periodística de esos años.

En la novela, el cronotopo de la provincia durante los años 80 se configura como un lugar antropológico, en términos de Augé (Los no lugares), en el

10 Las apariciones comienzan justo o paradójicamente cuando se inician los movimientos sociales -entre ellos, el movimiento secundario- en contra de la dictadura de Augusto Pinochet, lo cual justifica nuevamente la tesis del uso ideológico de ellas por el Servicio de Inteligencia. 
sentido de que concentra simbólica e imaginativamente el proceso de la memoria que realiza, desde el presente posdictatorial, la voz colectiva. Ésta reflexiona sobre el paso del tiempo y sus marcas en el espacio provinciano, en el pueblo que se caracteriza por ser justamente un lugar de paso para ir hacia otro lugar. "El pueblo nunca dejó de ser esto: una costra de viviendas y casas quinta y locales comerciales y escuelas con cancha de tierra, que se edificó en torno a una estación de trenes. Nunca tuvo una Plaza de Armas porque no fue necesaria. Nadie iba a quedarse aquí" (Bisama, Ruido 23). Por ello, esta provincia de Bisama podría ser leída como una fantasmagoría urbana, la promesa de un centro urbano del cual solo quedan los restos olvidados, y donde operan otras lógicas: "Los sujetos y objetos ruinosos adquieren un carácter fantasmagórico porque provienen de otro tiempo, son un desecho cultural que exhibe el rápido envejecimiento generado por la modernidad" (Sepúlveda, Chile urbano 13-4). Por lo mismo, la provincia de Ruido podría ser leída como una metáfora del país, de una subjetividad provinciana que presiente que lo real está siempre fuera de allí (Rojas Contreras 254); de una subjetividad provinciana particular que se vincula con el tiempo del horror: "[...] de la sensación de que todo está congelado artificialmente y que por lo tanto puede explotar de repente pues se mide a través del miedo permanente a que eso suceda, como si vivieras de prestado, como si el tiempo no fuera tuyo" (Bisama, "Fotos" 45).

A este lugar de tránsito llega desde otra provincia el niño-viajero Miguel Ángel Poblete, quien es el telón o imagen de fondo que permea el proceso de crecimiento de los que conforman la voz colectiva, el "nosotros".

Se vino acá siguiendo a su madre. Ella lo abandonó. Podemos imaginarlo ahí, al vidente que aún no es vidente, descendiendo por el mapa de Chile hasta llegar a un hogar de menores del pueblo; así, atravesando el país, al modo de esos personajes de una literatura infantil que avanzan por un bosque hostil, para terminar encontrándose a sí mismos (Ruido 20).

La marginalidad lo acompaña desde el norte al litoral central y se condice con la experiencia de los niños huérfanos de la historia de Chile. Su vida se inserta en la que definiera Gabriel Salazar en su libro Ser niño huacho en la historia de Chile (2006): "Los niños no son agentes activos en la historia adulta. O sea, en la gran historia de la patria. Menos aún los niños de la calle, los niños indigentes, los huachos [...]" (78). La Historia con mayúscula los ha olvidado, así como la familia y el Estado: 
Ahí no es difícil imaginar cómo el vidente, antes de ser tal cosa, era uno más de esos adolescentes perdidos en el mapa del lugar, pasando la tarde en los flippers, aspirando bencina, haciendo trabajos de jardinería, emborrachándose hasta perder la conciencia antes de pasar la tarde dormido en los bancos de la estación. El pueblo siempre fue cruel con ellos, los dejó a la intemperie en la plaza; jóvenes atrapados por el sol de la tarde (Bisama, Ruido 32).

Se dijo que padecía de mitomanía y mitocondria, y que era un experto en la Biblia antes de instalarse en el Centro Carlos Van Buren de Villa Alemana (Equipo APSI 20). A falta de una educación, se educó a sí mismo y logró articular un relato creíble en torno a la Virgen María influenciado por intereses ideológicos de otros: "María hablaba del fin del mundo, se declaraba anticomunista, y volvía - una y otra vez-sobre una posible invasión extranjera, pedía que los fieles rezaran el rosario por Rusia" (Bisama, Ruido 52). Miguel Ángel es el poseedor de la verdad de la dama de la Paz, el niño escogido justamente por su diferencia, pobreza e inocencia. Su locura es lucidez y una marca de elección: "El vidente era de los que vagaba, aunque la leyenda que construyó sobre sí mismo dice otra cosa: que siempre fue un elegido, que siempre estuvo señalado" (32). Se inserta satisfactoriamente en el imaginario religioso de la época.

El proceso de cambio del vidente - desde que pasa de adolescente marginal a vidente, luego a travestido y alcohólico, es decir, las transformaciones acontecidas durante la década del 80,90 y 2000 - son sintonizadas discursivamente con las de los niños y adolescentes, luego adultos, de la provincia en cuestión. Siguiendo a Grínor Rojo en su lectura de la novela, en Ruido priman ciertas acciones que marcan las etapas de aprendizaje: pedalear (los niños), rockear (los adolescentes) y recordar (los adultos) (190). Los niños de la provincia chilena siguieron sus vidas mientras escuchaban el murmullo de las apariciones: "En esa época empezamos a escuchar del milagro. La noticia corría en el boca a boca. El cuento se deformó, dejó de tener sentido. La Virgen se le aparecía a un niño y le decía cosas, la Virgen se aparecía en un cerro; el niño era un santo; el niño miraba al cielo, hacía milagros" (Bisama, Ruido 40). De hecho, el verbo conjugado "crecimos" se repite numerosas veces en un fragmento del capítulo "Los invasores del espacio" para enfatizar semánticamente en el cambio y la simultaneidad del proceso de los niños con el del vidente: “¿Cómo crecimos? Crecimos con el sonido de la voz de nuestros padres viniendo de lejos, convertida en un murmullo sin sentido que nos quemaba los oídos. Crecimos con el vidente y 
su sangre falsa. Crecimos con la sensación de que había un mundo ahí afuera que se estrellaba a veces con el nuestro [...]" (48).

El ruido permanente parece ser el tono o sonido del cronotopo de la provincia chilena en los 80 , pero a la vez también existían los silencios obligados para mantener la vida: "Nos prohibieron hablar del tema. Están matando gente, esto debe ser falso, dijeron. Al lado de la paranoia y el miedo, la Virgen y el vidente parecían un divertimento, un problema menor, una animita de postal. Tenían razón, eran los años duros. No lo sabíamos, pero estábamos rodeados por los fantasmas, abrazados por los muertos" (51). Los padres pedían silencio y se instalaba el ruido que venían de órbitas celestiales, y la muerte.

Bisama da cuenta de la apropiación marginal de los discursos del periodo con un lenguaje particular que es capaz también de evidenciar éstos a nivel de significante. La idea de "película" que recorre la crónica del autor titulada "La película del fin del mundo" (2007) refiere a uno de los tantos lenguajes que apelan al carácter artificial del hecho histórico y religioso. A las nociones de fuera y dentro de campo, a la cámara en movimiento que registra el escenario de la provincia en la crónica, se unen los conceptos de la imagen y el del ruido/murmullo articulados como significados y significantes en la novela Ruido. Cabe recordar aquí que el relato de la voz colectiva surge gracias a una imagen borroneada, un stencil: "La reproducción de la imagen que venía en el diario era malísima. La muchacha lo había conseguido: en esas líneas falsas estampadas sobre un muro viejo estaba el murmullo de la memoria" (Bisama, Ruido 162). El stencil ya es otra cosa, otra realidad, un simulacro de lo que fuera el vidente. Tanto el milagro como el vidente pertenecen, en el presente, al fuera de campo: "Lo que importa es la sombra difusa del rostro del vidente, esa sombra que es una musculatura deforme, que predice algo que está más allá de la imagen" (164) a pesar de que, en el tiempo-espacio de la provincia en los 80, fueron el centro del encuadre. En el presente enunciativo, eso que está más allá o el fuera del campo que la imagen borroneada materializa, permite el recuerdo y que se traiga al presente, la materialización fotográfica de los tiempos pasados: "Los stencils nos lanzaban al pozo de nuestras pesadillas [...] Dentro de ese pozo preguntábamos cómo habíamos envejecido, nosotros y las pesadillas, de un día para otro [...] Sacábamos cuentas. Pensábamos en la historia de la ciudad, en esa intensidad que había desaparecido y en cómo éramos felices en la ausencia de vértigo" (13).

En relación con lo anterior, el stencil funciona como Spectrum en términos de Barthes: "aquello que es fotografiado es el blanco, el referente, una especie de pequeño simulacro, de eidolon emitido por el objeto, que yo llamaría de 
buen grado el Spectrum de la fotografía porque esta palabra mantiene a través de su raíz una relación con espectáculo y le añade ese algo terrible que hay en toda fotografía: el retorno de lo muerto" (Barthes, La cámara lúcida 185). Es por ello que la voz plural afirma: "[e]ntendíamos el porqué de la imagen de los stencils: avanzando desde atrás en el calendario hasta el presente. La memoria es eso, incluso para los fantasmas: basura que cruza distancias siderales, escombros que quedan en sitios baldíos, restos de naufragio que atraviesan el mar helado, ruinas que flotan en el tiempo" (Bisama, Ruido 20). La imagen visual del stencil unida a las imágenes sonoras del ruido/murmullo se transforman en objetos particulares que denuncian y hacen evidente el tiempo pasado. Por lo mismo, el "nosotros" del hablante corresponde a un "gesto brumoso, al hecho de pensar la escritura y el acto de memoria como una especie de neblina, donde podía navegar en las versiones, jugar con las hilachas de la historia" (Jofré, "Sordos para siempre"). En este sentido, el yo personal y autoficcional de Bisama se esconde/enmascara y fragmenta en un "nosotros" que recuerda, desde el presente de la posdictadura, la provincia chilena de los 80 , y articula la imagen borroneada del vidente, el ruido y el tedio como los significantes poéticos de un pasado que vuelve.

\section{"ESCRITURA, ELECCIÓN Y REFUGIO": EL ESTUDIANTE DE LITERATURA Y EL ESCRITOR}

En varios relatos del escritor Alejandro Zambra (1975) -la novela Formas de volver a casa (2011), en los cuentos recopilados en Mis documentos (2014) y en la ópera prima Bonsái (2006) - la figura del estudiante de literatura que deviene después escritor es la clave de lectura. De hecho, una de las perspectivas centrales de la crítica académica que ha analizado su obra es en torno a la metarreflexión sobre el ejercicio literario y escritural. Si bien Nona Fernández y Álvaro Bisama se acercan también a la autoficción como estrategia literaria que permite ahondar en la escritura y en la reconstrucción de una memoria compartida, Zambra profundiza sobre este ejercicio reflexivo y articula un imaginario particular - cuyo punto de inicio es su propia experiencia-sobre el estudiante de literatura y el escritor. Por lo anterior, las siguientes páginas buscan dibujar dos ideas-imágenes conectadas para comprender la articulación de esta suerte de imaginario literario e intelectual: primero, la concepción de la literatura (lectura) y su ejercicio (escritura) como una condición marginal, 
pero, a la vez, como un signo de elección; segundo, la literatura como un refugio que evita el olvido.

Respecto de la primera, el niño narrador de Formas de volver a casa y Mis documentos cursa el segundo ciclo estudiantil -de $7^{\circ}$ a $4^{\circ}$ medio- en el Instituto Nacional. Desde su condición literal de estudiante secundario articula la idea-imagen de "personajes secundarios", secundarios por edad escolar, pero secundarios, sobre todo, porque eran muy niños para escribir la novela, la historia ${ }^{11}$. Sin embargo, el vacío de protagonismo histórico se llena de libros y de lecturas formativas o deformativas, porque el narrador recuerda que no leyó Madame Bovary de Gustave Flaubert ya que las descripciones realistas lo superaban, sino que vio la película de Vicente Minellli dos veces y recibió a cambio una nota 3,6 y un comentario de la profesora. Y recuerda que sus "profesores no querían entusiasmarnos sino disuadirnos, alejarnos para siempre de los libros. No gastaban saliva hablando sobre el placer de la lectura, tal vez porque ellos habían perdido ese placer o nunca lo habían sentido realmente" (Formas de volver a casa 57-58). Ser buen profesor, en ese entonces, era saberse con suerte los manuales de memoria, afirma el niño narrador. No obstante eso, la identificación literaria con un personaje secundario como Berta, la hija de Madame Bovary, dotaba de sentido su no protagonismo. Su vida de secundarios era similar a la de otros niños y, por lo mismo, su vida también era posible de novelar, la novela de los hijos marcada por los imaginarios filiativos y sociales de "la escuela pública [de excelencia], el imaginario militar y los libros regalados por la revista Ercilla" (Carreño, Av. Independencia 144). Entonces, a falta de muertos reales, abundaban los libros Ercilla.

Ahora bien, junto con saberse ahora personajes secundarios de la literatura y la historia, los mismos profesores reforzarán la idea de su marginalidad dentro de su exclusividad educacional en el liceo emblemático de la dictadura: "Nos dijo que éramos unos privilegiados, que habíamos recibido una educación de excelencia. Que habíamos tenido clases con los mejores profesores de Chile [...] Los humanistas son la escoria del Nacional, dijo" (Zambra, Mis documentos 111). Dentro de la formación académica tradicional y de élites,

11 Al igual que los compañeros de la escuela de Avenida Matta que articula Nona Fernández en Space Invaders, los del Instituto Nacional de Formas de volver a casa son también "demasiado niños", pero su activismo político no se traduce en muerte, sino en literatura. 
las humanidades ocupan también un lugar secundario. Ahora bien, esta disposición secundaria es vista por el narrador como un signo de elección, como una barrera que lo distanciaba de esa "[...] gente frustrada y tonta. Obsecuentes, pinochetistas. Huevones de mierda" (100). En ese sentido, la literatura y su ejercicio juvenil canalizaban una incomodidad, una energía diferente y trasformadora: "La rabia me hacía indestructible. Pero no solamente la rabia. También una confianza ciega o una cierta tozudez que nunca me ha abandonado. Porque hablaba bajo pero era fuerte. Porque hablo bajo pero soy fuerte. Porque nunca grito pero soy fuerte" (113). Los códigos y afectos son diferentes, y a la arrogancia de ciertos profesores se contrapone una valentía de otro tipo: "Me quedo clavado en esta frase: 'En lugar de gritar, escribo libros", (Formas de volver a casa 155). De hecho, tal como afirma el narrador niño, la literatura en esos años juveniles reemplaza al gran relato formativo y marco social de la religión:

Decidí renunciar y en ese mismo momento dejé de ser católico. Supongo que también entonces comenzó a extinguirse del todo el sentimiento religioso. Nunca tuve, en todo caso, esos devaneos racionales sobre la existencia de Dios, quizás porque después empecé a creer, de manera ingenua, intensa y absoluta, en la literatura (Mis documentos 24).

La religión católica y su imaginario protector es sustituido por la literatura. Entonces, "la vida religiosa, el temor al castigo de Dios, se nos dibuja como una fe que cae en la niñez para ser reemplazada por la esperanza y protección de los libros" (Daza 282). La confesión como rito central de la formación juvenil y religiosa se traslada al rito poético de la autoconfesión, del sacarse la máscara para mostrar el verdadero yo, acto mediado -ya no por un sacerdotesino por la ficción, y el espacio de protección que construye.

Por lo señalado antes, el juego de la lectura/escritura en la adolescencia pasa al ejercicio escritural en la adultez:

Ahí en el colegio había un espacio literario: uno jugaba a ser escritor. Me gustaba mucho leer y lo pasábamos muy bien. Nos íbamos, camuflando el uniforme, a tomar al Indianápolis. Nos creíamos más o menos inmortales. Y la literatura dejó de ser un juego como a los 20, 21 años, cuando se convirtió en un hábito. Pero, sí, mucho tiempo jugábamos al deporte más extremo que hay en Chile, que es ser poeta. El único deporte -además- en que hemos ganado campeonatos mundiales (Díaz Oliva, "Los 80 según Zambra”). 
No obstante los campeonatos ganados, el camino de estudiante de literatura secundario y universitario a escritor nacional es uno pedregroso, que corre caminos alternos al de la mayoría de los chilenos. Se podía ser escritor, sin embargo, no se podía vivir de la literatura. "Ya era escritor entonces, para ser justos: ya había escrito algunos cuentos, y un escritor es alguien que escribe, bien o mal pero escribe, poco o mucho pero escribe, así como un asesino es alguien que mata, a uno o a varios, a un desconocido o a su padre, pero mata" (Zambra, Mis documentos 193). En el cuento "Larga distancia", el narrador escritor adulto da cuenta de los distintos oficios o trabajos que debe hacer para sobrevivir: telefonista nocturno de asistencia en viaje; profesor de cursos donde se enseña a escribir y, algunas veces, a pronunciar bien en un instituto que es clausurado sin previo aviso; y clases de apreciación literaria a un hombre que no quiere saber de literatura, sino de la "excéntrica" vida del profesor. El protagonista de Bonsái es también un Licenciado en Literatura. Para costear sus gastos, intenta ser transcriptor de la novela de un conocido escritor, pero fracasa en el intento. No recibe una remuneración para vivir, pero sí escribe una novela haciéndose pasar por otro escritor. Es un escritor falso que, en el camino, se convierte en uno verdadero. Entonces, la precariedad económica sería también un signo de elección.

Cabe volver, ahora, al título de la novela Formas de volver a casa. El significado que adquiere el término casa es complejo puesto que se la puede entender como metáfora de la literatura y la escritura (Willem 28), pero pensar la casa como metáfora de la literatura reafirmaría la separación entre ficción y realidad y lo que Formas de volver a casa y también Bonsái hacen es justamente problematizar estos límites o que, por lo menos, es imposible diferenciarlas. Si se piensa la casa física como un imaginario de protección, cabe recordar que el protagonista, de hecho, no vuelve ni a la casa de sus padres en Maipú ni donde Eme, su exmujer. Por ello, hace más sentido entender la casa como un espacio imaginario - más confuso y menos arbitrario- que tiene que ver con la infancia en el sentido de recordar, de vincular experiencia y lenguaje en los términos que Agamben propone en Infancia e historia. Entonces, volver a casa es volver a la infancia y al lenguaje. Y la escritura se instaura como otro hogar. Según Willem, las obras de Zambra podrían ser leídas desde la idea de que la casa es al mundo exterior como la literatura a la realidad (28). Entonces, casa y ficción ofrecen un cierto resguardo, aunque sea precario, puesto que a lo largo de la novela la mayoría de las casas se vienen abajo o ya no resultan cómodas (Garcés, "El silencio de los hijos"), o los que las habitaban ya no están. Volver a casa es volver a la literatura como espacio predilecto que permite construir un relato, una casa propia aunque ésta sea 
susceptible y permeable: "volver a casa significa aquí volver a la vida real, pero mediante la ficción" (Willem 33).

Si en Formas de volver a casa y en Mis documentos se hace evidente que la literatura reemplaza la religión, y cumple algunos de sus fines confesionales -sacarse las máscaras al mismo tiempo de ponérselas-, la literatura se articula imaginariamente como una casa y como refugio. En este punto, se establece una distinción entre las novelas Bonsái y Formas de volver a casa, puesto que en la primera, el protagonista termina a la deriva -al final del relato, Julio sabe de la muerte de Emilia y gasta los billetes recién ganados en transitar sin rumbo y sin comunicación por la ciudad de Santiago. En esa historia, la literatura es el fetiche presente que evidencia la ausencia de Emilia y le permite el recuerdo, el refugio del no olvido amoroso. Es decir, también es refugio como en Formas de volver a casa, pero la incomodidad y la nostalgia son mucho mayores.

Si se entiende la literatura como refugio, cabe la pregunta de refugio contra quién o contra qué. Se podría afirmar que un refugio contra el olvido porque ello dotaría de sentido a la literatura de los hijos. A la vez que la literatura de los hijos trata sobre cómo lidiar en la posdictadura con una herencia conflictiva, la literatura como espacio y formato pertenece exclusivamente a los hijos, es de ellos, y los diferencia, a la vez, de los padres que articulan supuestamente la Historia. La literatura es una casa particular que permite acceder al pasado, es el espacio por derecho conquistado. Se supone que los niños de los 80 no podían hablar ni actuar políticamente porque justamente eran "demasiado niños", pero sí pueden hablar, en el presente posdictatorial, en el espacio de la literatura y sí se puede recordar en y desde la infancia como perspectiva y contexto: a los hijos "[n]os une el deseo de recuperar las escenas de los personajes secundarios. Escenas razonablemente descartadas, innecesarias, que sin embargo coleccionamos incesantemente" (Formas de volver a casa 122).

\section{ÚLTIMAS OBSERVACIONES}

Tras trazar tres ideas-imágenes principales que construyen los narradores de las obras ficcionales de Nona Fernández, Álvaro Bisama y Alejandro Zambra, no cabe duda de que la perspectiva autoficcional articulada por Zambra propone una reconciliación más satisfactoria entre los imaginarios construidos ficcionalmente y la realidad. Más allá de la imagen poética del terremoto y 
soledad que da fin a la novela Formas de volver a casa (2011), el narrador nunca pierde la voz autorreflexiva que instituye la infancia, en el sentido de la comunicabilidad de la experiencia, y la escritura como salida positiva a un presente conflictivo entre los hechos traumáticos del pasado y el presente incómodo. El "yo" de Formas de volver a casa y Mis documentos se siente bien y cómodo en el intento de representar a un "nosotros", a un colectivo que se siente identificado con los imaginarios sociales y con la literatura como espacio intocable y de elección. En la obra de Zambra, la posibilidad de una reconciliación afectiva del conflicto es factible, aunque éste persista.

A diferencia de Zambra, Álvaro Bisama, que articula, desde un inicio y literalmente, un "nosotros" atravesado por el ruido y el tedio de la provincia chilena, pareciera no poder evitar plasmar un desencanto mayor ante la imposibilidad, para él, de articular un relato de historia, sino solo uno de memoria y de una fragmentada. Por ello, construye una voz más ambigua e indeterminada, que reitera y susurra infatigablemente el sentimiento de fracaso y decepción que atraviesa la provincia de los años 80 hasta ahora. A su vez, otorga un lugar central al vidente -y su imagen actual deslavadacomo personaje representativo de la marginalidad social en nuestra historia nacional, así como a los discursos del periodo que se reconfiguran también como basuras, fantasmas y ruidos que conforman la neblina de la memoria.

Por su parte, Nona Fernández subraya, con mayor hincapié, en el desencanto y en la pérdida a través de la imagen poética de la muerte vinculada el juego juvenil. Propone en Space invaders, y en su obra en general, una salida al horror que está vinculada a la muerte y al sueño de muerte. Los niños del pasado jugaban y morían. Los adultos del presente tienen pesadillas en colchones desperdigados por todos lados. La voz plural, al igual que en la novela de Bisama, es más poética y no busca dar explicaciones o justificar acciones, sino dar cuenta de una tensión y conflicto que persisten en afectos como el desencanto y el horror frente a una violencia real y simbólica, y así explicar ciertas derrotas históricas.

Para finalizar, se vuelve a la pregunta ya metaficcional que subyace a este análisis sobre por qué los escritores en cuestión -y otros del grupo de los hijos - optan por relatos ficcionales con protagonistas infantiles y juveniles. Pareciera ser que la literatura $-\mathrm{y}$ el arte en general- permiten a estos autores salirse de la lógica filiativa negativa -de los imaginarios deformativos de la dictadura- que exponen en sus relatos y entrar en una afiliativa propia y única: la escritura. En este sentido, antes se planteó la idea de que este afán de reconstruir el pasado de infancia se relacionaba con el pago de una deuda 
ética y estética que les permitiría pasar de ser protagonistas secundarios de la historia política y social del pasado reciente a protagonistas de la escritura en el tiempo actual. Siguiendo esa idea, la construcción de una voz plural en el caso de las novelas, por sobre una singular, confirma este afán de imaginar una perspectiva grupal y comunitaria, por sobre una personal e individual, que devuelve así, a la escritura ficcional, un rol central en la articulación de la memoria colectiva y compartida del pasado reciente.

Las obras analizadas se enmarcan dentro de lo que se entiende por una literatura que otorga un lugar preponderante a la experiencia y a la posibilidad de su comunicabilidad, en el mundo ficcional. De alguna forma, estos hijosescritores se hacen cargo estéticamente de la violencia dictatorial pasada, que inicia con el hecho disruptivo y escogido por los mismos de la memoria que es el golpe militar, y que se sigue expresando en otras dinámicas y estrategias en el presente posdictatorial. Pareciera que, en todos los autores mencionados, está la intención -más o menos verbalizada- de mitigar una incomodidad latente -y aún por definir y comprender- que persiste desde sus orígenes, y que les impide desvincularse del pasado. Por lo mismo, la persistencia del conflicto permite la continuidad afectiva entre la dictadura y la posdictadura, puesto que obliga a mirar atrás, obliga a observar, con mayor detención, el pasado.

\section{BIBLIOGRAFÍA}

Agamben, Giorgio. Infancia e historia. Ed. Adriana Hidalgo. Buenos Aires: 2011.

Augé, Marc. Los no lugares. Espacios de anonimato. Barcelona: Gedisa, 1996.

Baczko, Bronislaw. Los imaginarios sociales. Memorias y esperanzas colectivas. Buenos Aires: Nueva Visión, 1991.

Barthes, Roland. La cámara lúcida. Notas sobre la fotografía. Barcelona: Paidós, 1989.

Benjamin, Walter. "Sobre el concepto de historia". Estética y política. Buenos Aires: Las Cuarenta, 2009.

Bisama, Álvaro. Ruido. Santiago: Alfaguara, 2012.

"La película del fin del mundo". Dios es chileno. Santiago de Chile:

Planeta, 2007.

"Fotos". Volver a los 17. Recuerdos de una generación en dictadura. Ed. Óscar Contardo. Santiago: Planeta, 2013.

Carreño, Rubí. Av. Independencia. Literatura, música e idea de Chile disidente. Santiago: Cuarto Propio, 2013. 
Daza, Paulina. "Mis Documentos". Alpha 38 (2014): 281-284.

Díaz Oliva, Antonio. "Los 80 según Zambra". Revista Qué pasa. 14 de abril, 2011. Recuperado de: http://www.quepasa.cl/articulo/cultura/2011/04/6-5491-9-los-80-segun-zambra. shtml/\#note

Equipo Apsi. "Vida y milagros de la Virgen de Peñablanca". APSI 163 (1985): 19-23. Recuperado de: http://www.memoriachilena.cl/archivos2/pdfs/MC0041475.pdf.

Fernández, Nona. Space Invaders. Santiago: Alquimia Ediciones, 2013.

Liceo de niñas. Santiago: Ediciones Oxímoron, 2016.

"Hijos". Volver a los 17. Recuerdos de una generación en dictadura. Ed. Óscar Contardo. Santiago: Planeta, 2013.

Garcés, Gonzalo. "El silencio de los hijos". Revista Ñ 24 de junio, 2011. Recuperado de: http://www.revistaenie.clarin.com/rn/literatura/resenas/Formas_de_volver_a_casaZambra_0_BkXQC9g6Dmx.html.

Jelin, Elizabeth. "El género en las memorias”, “¿De qué hablamos cuando hablamos de memorias". Los trabajos de la memoria. Madrid: Siglo XXI Editores, 2002: 99-116.

Jofré, Alejandro. "Sordos para siempre". Paniko.cl. octubre de 2012. Recuperado de: http:// www.paniko.cl/2012/10/alvaro-bisama-ruido-sordos-para-siempre/.

Hirsch, Marianne. La generación de la posmemoria. Escritura y cultura visual después del Holocausto. Madrid: Carpe Noctem, 2015.

Huizinga, Johan. Homo ludens. Buenos Aires: Emecé, 2012.

Rojas Contreras, Sergio. "Profunda superficie: memoria de lo cotidiano en la literatura chilena". Revista Chilena de Literatura 89 (2015): 231-256.

Rojo, Grínor. "Pedalear, rockear, crecer y recordar: Ruido, de Álvaro Bisama”. Taller de Letras 57 (2015): 175-194.

Said, Edward. W. El mundo, el texto y el crítico. Barcelona: Debate, 2004.

Salazar, Gabriel. Ser niño huacho en la historia de Chile (siglo XIX). Santiago: LOM, 2006.

Sepúlveda Eriz, Magda. Ed. Chile urbano: la ciudad en la literatura y en el cine. Santiago: Editorial Cuarto Propio y Ediciones Universidad Católica, 2013.

"La construcción de identidades, sus imaginarios y su posición en la literatura". Taller de Letras 32 (2003): 67-78.

Sepúlveda Hidalgo, Paulina. "Conversación con Nona Fernández. Ponerse en la piel del otro". Revista de Humanidades 29 (2014): 249-261.

Vásquez, Malva Marina. "Memoria urbana y ciudades abyectas: Nona Fernández". Chile urbano: la ciudad en la literatura y el cine. Magda Sepúlveda. Ed. Santiago: Editorial Cuarto Propio y Ediciones Universidad Católica, 2013. 308-324.

Willem, Bieke. "Metáfora, alegoría y nostalgia: La casa en las novelas de Alejandro Zambra". Acta Literaria 45 (2012): 25-42.

Zambra, Alejandro. Formas de volver a casa. Santiago: Anagrama, 2012.

Bonsái. Santiago: Anagrama, 2012.

Mis documentos. Santiago: Anagrama, 2014. 